\title{
UTILIZAÇÃO DE TORTA DE MAMONA E ESTERCO CAPRINO EM AMENDOIM (Arachis hypogaea L.) cv. Br1
}

\author{
EL USO DE RICINO Y EL ESTIÉRCOL DE CABRA EN EL MANÍ (Arachis hypogaea \\ L.) cv. Br1
}

\section{USE OF CASTOR BEAN AND GOAT MANURE IN PEANUT (Arachis hypogaea L.) cv. br1}

\author{
Yara Sabrina Alves LEITE ${ }^{1}$ \\ Mário Leno Martins VÉRAS ${ }^{2}$ \\ José Sebastião de MELO FILHO ${ }^{3}$ \\ Urandy Alves de MELO ${ }^{4}$ \\ Fabiana Xavier COSTA ${ }^{5}$
}

RESUMO: Objetivou-se com esta pesquisa estudar a utilização de torta de mamona e esterco caprino em amendoim (Arachis hypogaea L.) cv. Br1. O ensaio foi conduzido no período de Janeiro a Abril de 2015, em campo localizado na Escola Agrotécnica do Cajueiro, pertencente à Universidade Estadual da Paraíba - UEPB, Campus - IV. Adotou-se o delineamento experimental de blocos ao acaso, com esquema fatorial 4 × 2, com 8 tratamentos, com quatro quantidades de adubação orgânica: $\left(0,2,4\right.$ e 6 t/ha $\left.{ }^{-1}\right)$ e duas fontes de adubação orgânica: (F1 = torta de mamona e F2 = esterco caprino), com quatro repetições, totalizando 32 unidades experimentais. Verificou-se resposta significativa do amendoim para tratamentos impostos. Observou-se que as quantidades de adubação orgânica influenciaram estatisticamente todas as variáveis analisadas a nível de $(\mathrm{p}<0,01)$ de probabilidade. Para o efeito das fontes de adubação orgânica, as variáveis área foliar e comprimento da raiz responderam significativamente a nível de $\mathrm{p}<0,05$ e área foliar total a nível de $\mathrm{p}<0,01$, não sendo observada significância para o número de botões florais. A quantidade máxima de $6 \mathrm{t} / \mathrm{ha}^{-1}$ de adubação orgânica promoveu melhor o crescimento de amendoim. Recomenda-se a utilização de esterco caprino no cultivo de amendoim.

Palavras-chave: Arachis hypogaea L., adubos orgânicos, agroecologia.

RESUMÉN: El objetivo de este estudio de investigación el uso de semillas de ricino y el estiércol de cabra en el maní (Arachis hypogaea L.) cv. Br1. La prueba se llevó a cabo de enero a abril de 2015, situado en el campo Agrotécnica Escuela de anacardo, perteneciente a la Universidad del Estado de Paraíba - UEPB, Campus - IV. Adoptó el diseño experimental de bloques al azar con un factorial $4 \times 2$ con ocho tratamientos, con cuatro cantidades de

\footnotetext{
${ }^{1}$ Graduanda em Licenciatura em Ciências Agrárias, Universidade Estadual da Paraíba (UEPB), Catolé do Rocha - PB. E-mail: yarasabrina_al@hotmail.com

${ }^{2}$ Mestrando em Agronomia, Universidade Federal da Paraíba (UFPB), Areia - PB. E-mail: mario.deus1992@bol.com.br

${ }^{3}$ Mestre em Sistemas Agroindustriais, Universidade Federal de Campina Grande (UFCG), Pombal - PB. E-mail: sebastiaouepb@yahoo.com.br

${ }^{4}$ Graduação em Licenciatura em Ciências Agrárias, Universidade Estadual da Paraíba (UEPB), Catolé do Rocha

- PB. E-mail: urandyuepb@yahoo.com.br

5 Prof. Dra. da Universidade Estadual da Paraíba (UEPB), Catolé do Rocha - PB.

E-mail: fabyxavierster@gmail.com
} 
fertilización orgánica: $\left(0,2,4\right.$ y $6 \mathrm{t} /$ ha- $\left.^{1}\right)$ y dos fuentes de fertilización orgánica: $(\mathrm{F} 1$ = ricino pastel de frijol y F2 = estiércol de cabra), con cuatro repeticiones, con un total de 32 unidades experimentales. Hubo una respuesta significativa del maní para tratamientos fiscales. Se observó que la cantidad de abono orgánico estadísticamente todas las variables influyen en el nivel ( $\mathrm{p}<0,01)$ la probabilidad. Para este propósito las fuentes de fertilizantes orgánicos, las variables de área foliar y longitud respondieron significativamente al nivel de la raíz de $\mathrm{p}$ $<0,05$ y el área foliar total en el nivel de $\mathrm{p}<0,01$ importancia no se observó para el número de brotes . La cantidad máxima de $6 \mathrm{t} /$ ha ${ }^{1}$ fertilización mejor crecimiento de maní orgánico. Se recomienda el uso de estiércol de cabra en el cultivo de maní.

Palabras-chave: Arachis hypogaea L., fertilizantes orgánicos, la agroecología.

\begin{abstract}
The objective of this research study the use of castor bean and goat manure in peanut (Arachis hypogaea L.) cv. Br1. The test was carried out from January to April 2015, located in the field Agrotechnical School of cashew tree, belonging to the State University of Paraíba - UEPB, Campus - IV. It adopted the experimental design of randomized blocks with a factorial $4 \times 2$ with eight treatments, with four amounts of organic fertilization: $(0,2,4$ and $\left.6 \mathrm{t} / \mathrm{ha}^{-1}\right)$ and two sources of organic fertilization: $(\mathrm{F} 1=$ castor bean cake and $\mathrm{F} 2=$ goat manure), with four repetitions, totaling 32 experimental units. There was a significant response from the peanut for tax treatments. It was observed that the amount of organic fertilizer statistically all variables influence the level $(\mathrm{p}<0.01)$ probability. For this purpose sources of organic fertilizer, the leaf area and length variables significantly responded to the root level of $p<0,05$ and total leaf area at the level of $p<0.01$ significance was not observed for the number of buds. The maximum amount of $6 \mathrm{t} /$ ha ${ }^{1}$ organic fertilization best peanut growth. It is recommended the use of goat manure in peanut cultivation.
\end{abstract}

Keywords: Arachis hypogaea L., organic fertilizers, agro-ecology.

\title{
INTRODUÇÃO
}

A cultura do amendoim (Arachis hypogaea L.) pertence à classe das oleaginosas, apresentando grande relevância econômica. É cultivado na maioria das regiões, devido sua ampla utilização, na indústria química e alimentícia. No semiárido é tido como uma fonte de renda para diversos agricultores e pequenos produtores (FREITAS, 2011). A área de cultivo dessa cultura nos anos de 2010/2011 foi de 12 mil hectares, com uma produtividade de aproximadamente $900 \mathrm{~kg} / \mathrm{ha}(\mathrm{CONAB}, 2012)$.

O destaque dessa cultura está relacionado à alta capacidade de adaptação a seca, especialmente no nordeste brasileiro, devido a suas características morfológicas e físiológicas. Contudo, um dos problemas atuais no cultivo de amendoim no são às variações climáticas, submetendo a diversos riscos, mesmo sendo uma cultura adaptável (GRACIANO et. al, 2011). 
Uma das características do cultivo orgânico é que há o manejo correto e conservação do solo para se adquirir adequadas características físicas, químicas e biológicas. Para isso, diversos fatores influenciam, as quais são: o solo deve apresentar quantidade equilibrada de nutrientes, altos teores de matéria orgânica, equilíbrio biológico, estrutura livre de agroquímicos (BORGES e BETTIOL, 2010).

Para o aumento da produtividade outro fator que influencia é a adubação, que quando bem conduzida proporciona aumentos significativos na produtividade na maioria das plantas cultivadas. É um ponto essencial na produção agrícola, podendo ser feita em baixo custo de investimento, contudo, é preciso ser feito de forma correta evitando o uso desnecessário de certos nutrientes que na maioria das vezes pode até reduzir a produtividade das culturas (PEREIRA et al., 2014).

Objetivou-se com esta pesquisa estudar a utilização de torta de mamona e esterco caprino em amendoim (Arachis hypogaea L.) cv. Br1.

\section{MATERIAL E MÉTODOS}

O ensaio foi conduzido no período de Janeiro a Abril de 2015, em campo localizado no Centro de Ciências Humanas e Agrárias, na Escola Agrotécnica do Cajueiro, pertencente à Universidade Estadual da Paraíba - UEPB, Campus - IV, município de Catolé do Rocha/PB (6²0’38”S; 3744’48”W) e 275 metros de altitude. O clima do município, de acordo com a classificação de Koppen, é do tipo BSW', ou seja, quente e seco do tipo estepe, com temperatura média mensal superior a $18^{\circ} \mathrm{C}$, durante todo o ano.

Foi adotado o delineamento experimental adotado foi o de blocos ao acaso, com esquema fatorial 4 x 2, com 8 tratamentos, com quatro quantidades de adubação orgânica: (0, 2, 4 e $6 \mathrm{t} /$ ha $\left.^{-1}\right)$ e duas fontes de adubação orgânica: $(\mathrm{F} 1$ = torta de mamona e F2 = esterco caprino), com quatro repetições, totalizando 32 unidades experimentais.

O solo utilizado foi classificado como Neossolo flúvico de textura franco argilo arenoso. Foram coletadas amostras na camada de 0 a $20 \mathrm{~cm}$ em área localizada no campus da UEPB. Da amostra de solo utilizada para o preenchimento dos sacos de polietileno foi retirada uma sub-amostra para ser analisada quimicamente e apresentou as seguintes características: $\mathrm{Ca}=4,63\left(\mathrm{cmol}_{\mathrm{c}} / \mathrm{dm}^{3}\right) ; \mathrm{Mg}=2,39\left(\mathrm{cmol}_{\mathrm{c}} / \mathrm{dm}^{3}\right) ; \mathrm{Na}=0,30\left(\mathrm{cmol}_{\mathrm{d}} / \mathrm{dm}^{3}\right) ; \mathrm{K}=$ $0,76\left(\mathrm{cmol}_{\mathrm{c}} / \mathrm{dm}^{3}\right) ;$ Soma de bases $-\mathrm{SB}=8,08\left(\mathrm{cmol}_{\mathrm{c}} / \mathrm{dm}^{3}\right) ; \mathrm{H}=0,00\left(\mathrm{cmol}_{\mathrm{c}} / \mathrm{dm}^{3}\right) ; \mathrm{Al}=0,00$ $\left(\mathrm{cmol}_{\mathrm{C}} / \mathrm{dm}^{3}\right) ; \mathrm{CTC}=8,08$ e Matéria orgânica $=1,88 \%$. 
A água utilizada na irrigação apresentou condutividade elétrica de $0,8 \mathrm{dS} / \mathrm{m}$. A análise da água foi realizada pelo Laboratório de Irrigação e Salinidade (LIS) do Centro de Tecnologia e Recursos Naturais da Universidade Federal de Campina Grande - UFCG e apresentou as seguintes características químicas: $\mathrm{pH}=7,53 ; \mathrm{Ca}=2,30\left(\mathrm{cmol}_{\mathrm{c}} / \mathrm{dm}^{3}\right) . \mathrm{Mg}=1,56$ $\left(\mathrm{cmol}_{\mathrm{C}} / \mathrm{dm}^{3}\right) ; \mathrm{Na}=4,00\left(\mathrm{cmol}_{\mathrm{c}} / \mathrm{dm}^{3}\right) ; \mathrm{K}=0,02\left(\mathrm{cmol}_{\mathrm{c}} / \mathrm{dm}^{3}\right) ;$ Cloreto = 3,90( $\left(\mathrm{cmol}_{\mathrm{c}} / \mathrm{dm}^{3}\right)$; Carbonato $=0,57\left(\mathrm{cmol}_{\mathrm{c}} / \mathrm{dm}^{3}\right) ;$ Bicarbonato $=3,85\left(\mathrm{cmol}_{\mathrm{c}} / \mathrm{dm}^{3}\right) ; \mathrm{RAS}=2,88\left(\mathrm{mmol}_{\mathrm{c}} \mathrm{l}^{-1}\right)^{1 / 2} \mathrm{e}$ Classificação Richards (1954) com $\mathrm{C}_{3} \mathrm{~S}_{1}$.

Foi feita a análise química da torta de mamona e apresentou as seguintes características: Umidade $=7,5 ;$ Proteína Bruta $=11,93 \% ; \mathrm{CZ}=12,6 \% ; \mathrm{N}=1 \% ; \mathrm{P}=1,91 \% ; \mathrm{P}_{2} \mathrm{O}_{5}=0,12 \% ; \mathrm{K}$ $=0,97 \% ; \mathrm{K}_{2} \mathrm{O}=4,61 \% ; \mathrm{C}=5,54 \% ; \mathrm{Ca}=1,27 \% ; \mathrm{O}=1,78 \% ; \mathrm{Mg}=0,30 \% ; \mathrm{MgO}=0,53 \% ; \mathrm{S}$ $=0,17 \% ; \mathrm{MO}=87,39 \%$.

A análise química do esterco caprino constou os seguintes atributos: $\mathrm{N}=21,9 \mathrm{~g} \mathrm{~kg}^{-1}$; $\mathrm{MO}=0,37 \mathrm{~g} \mathrm{~kg}^{-1} ; \mathrm{P}_{2} \mathrm{O}_{5}=11,6 \mathrm{~g} \mathrm{~kg}^{-1} ; \mathrm{K}_{2} \mathrm{O}=3,7 \mathrm{~g} \mathrm{~kg}^{-1} ; \mathrm{CaO}=39,4 \mathrm{~g} \mathrm{~kg}^{-1} ; \mathrm{MgO}=7,0$ e S $=2,4$.

Para as unidades experimentais foram utilizados vasos plásticos de $60 \mathrm{~L}$, tendo como medidas $57 \mathrm{~cm}$ de altura, $40 \mathrm{~cm}$ de diâmetro superior e $26,5 \mathrm{~cm}$ de diâmetro inferior, cujo solo foi peneirado e misturado com a torta de mamona ou esterco caprino.

O semeio foi realizado em saquinhos, utilizando quatro sementes de amendoim cv. Br1 distribuídas e distanciadas de forma equidistante na profundidade de $2 \mathrm{~cm}$. Aos 20 dias após semeio (DAS) as mudas foram transplantadas para os vasos. Durante a condução do experimento, foram efetuadas capinas manuais, conforme as necessidades de manutenção da cultura no limpo.

O suprimento de água às plantas foi fornecido através de recipientes. As regas foram realizadas em um único turno diário. $\mathrm{O}$ volume aplicado foi estimado com base no $\mathrm{Kc}$ da cultura.

Foram ainda adicionados $60 \mathrm{~kg} / \mathrm{ha}$ de amônia como fonte de nitrogênio, e $30 \mathrm{~kg} / \mathrm{ha}$ de superfosfato simples como fonte de fósforo. A aplicação de amônia foi feita em duas etapas, a primeira em fundação no momento do transplante das mudas para os vasos, utilizando-se 1/3 da dosagem, e a segunda no inicio da floração, utilizando-se $2 / 3$ da dosagem, completando assim os $60 \mathrm{~kg} / \mathrm{ha}$ de amônia.

Aos 90 dias após emergência (DAE) foram avaliadas: área foliar, área foliar total, número de botões florais, comprimento da raiz, peso seco da raiz, peso seco do caule, peso seco da folha e peso seco total. 
Para a medida da área foliar foram consideradas as folhas que apresentaram comprimento mínimo de $1,0 \mathrm{~cm}$, mensurando-se o comprimento da nervura principal da folha $\mathrm{x}$ largura $\mathrm{x}$ fator de ajuste $(0,5)$. Para o cálculo da área foliar total, foi realizado multiplicandose a área foliar unitária pelo número de folhas. O número de botões florais foi realizado através da contagem. $\mathrm{O}$ comprimento da raiz foi mensurado através de uma régua graduada em centímetro no final do ciclo da cultura. Já para o peso seco da raiz, peso seco do caule e peso seco da folha, as parte vegetativas das mesmas foram separadas, acondicionadas em sacos de papel devidamente identificados e colocadas para secar em estufa de ventilação forçada à temperatura de $60{ }^{\circ} \mathrm{C}$ sendo pesados através de uma balança de precisão. Para o cálculo do peso seco total, foram somados os valores obtidos no peso seco da raiz, peso seco do caule, peso seco da folha.

Os dados obtidos foram submetidos à análise de variância (Teste F) e teste de Tukey a 5\% de probabilidade e comparados através de modelos de regressão (FERREIRA, 2007).

\section{RESULTADOS E DISCUSSÃO}

Verificou-se resposta significativa do amendoim para tratamentos impostos (Tabela 1). Observou-se que as quantidades de adubação orgânica influenciaram estatisticamente todas as variáveis analisadas a nível de $(\mathrm{p}<0,01)$ de probabilidade. Para o efeito das fontes de adubação orgânica, as variáveis área foliar e comprimento da raiz responderam significativamente a nível de p<0,05 e área foliar total e número de botões florais a nível de $\mathrm{p}<0,01$. Não houve interação entre os fatores. Os coeficientes de variação oscilaram entre 8,50 a 16,02\% sendo considerados baixos a médios (PIMENTEL GOMES, 2000).

Tabela 1. Resumo das análises de variância referente à área foliar (AF), área foliar total (AFT), número de botões florais (NBC) e comprimento da raiz (CR) de amendoim submetido a diferentes quantidades (Q) e fontes (F) de adubação orgânica.

\begin{tabular}{lccccc}
\hline Fonte de variação & GL & \multicolumn{4}{c}{ Quadrados Médios } \\
\hline & & AF & AFT & NBF & CR \\
Quantidades & 3 & $8,94 * *$ & $8987,37 * *$ & $832,17^{* *}$ & $32,25 * *$ \\
Regressão Linear & 1 & $24,40 * *$ & $24206,4 * *$ & $2325,62 * *$ & $32,400^{\mathrm{ns}}$ \\
Regressão Quadrática & 1 & $0,28^{\mathrm{ns}}$ & $2244,50 * *$ & $120,12^{* *}$ & $55,12^{* *}$ \\
Fontes & 1 & $0,78 *$ & $2312 * *$ & $3,12^{* *}$ & $84,50 *$ \\
Interação Q x F & 3 & $7,86^{\mathrm{ns}}$ & $8997,75^{\mathrm{ns}}$ & $31,45^{\mathrm{ns}}$ & $96,91 \mathrm{~ns}$ \\
Resíduo & 24 & 0,19 & 108,27 & 8,20 & 8,62 \\
Desvio Padrão & 1 & 0,15 & 511,22 & 50,62 & 18,22 \\
CV $(\%)$ & - & 12,60 & 16,02 & 8,50 & 15,26 \\
\hline
\end{tabular}

CV: Coeficiente de Variação; GL: Grau de liberdade, ${ }^{*}$, ** significativo 5\% e a $1 \%$, respectivamente, e ${ }^{\text {ns }}$ não significativo, pelo teste $\mathrm{F}$ 
Foi observado para a área foliar um efeito significativo a nível de $(\mathrm{p}<0,01)$ de probabilidade, com uma resposta linear crescente conforme o aumento das quantidades de adubação orgânica, apresentando superioridade para os tratamentos que receberam a quantidade máxima de adubação orgânica 6 t/ ha ${ }^{-1}$ (figura 1A). Para as fontes de adubação, observou-se que os menores valores predominaram na torta de mamona (F1) (figura 1B).

Freitas et a. (2012) estudando a adubação orgânica no sulco de plantio e sua influência no desenvolvimento do sorgo observaram que os melhores resultados foram obtidos com a quantidade de 10 t/ ha ${ }^{-1}$ de adubação orgânica. Campos (2012) também observou os melhores resultados da área foliar submetidos a taxa de $92,25 \mathrm{~cm}^{2}$ por unidade de matéria orgânica aplicada ao solo.

Sá et al. (2014) trabalhando com a formação de mudas de maracujazeiro amarelo com diferentes doses de esterco caprino e volumes do substrato verificaram que o aumento das doses de esterco caprino proporcionaram os maiores valores 689,4 e 833,7 cm2 planta-1.

A

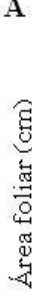

영

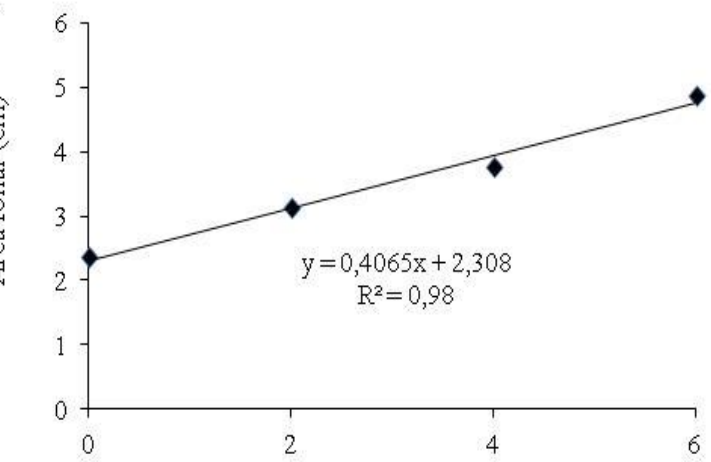

Quantidades de adubação orgânica $\left(\right.$ tha $\left.\mathrm{h}^{-1}\right)$
B

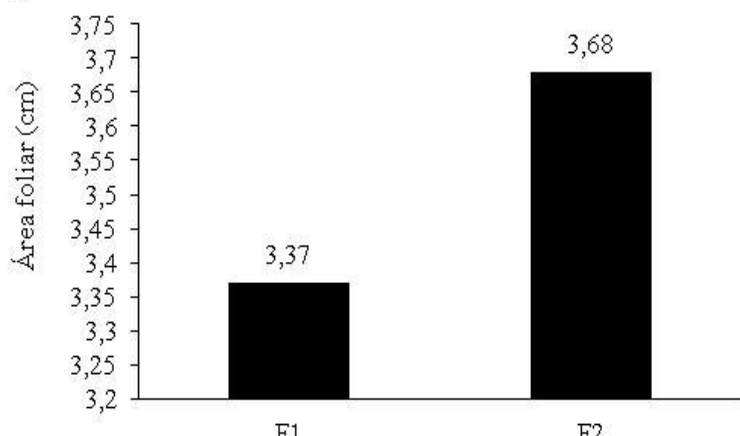

Fontes de adubação orgânica

Figura 1: Efeito de quantidades de adubação orgânica $(\mathrm{A})$ e fontes de adubação orgânica (B) na área foliar de amendoim

As quantidades de adubação orgânica influenciaram significativamente a área foliar total (figura 2A) observando-se uma resposta linear crescente onde o maior valor encontrado foi na quantidade máxima de adubação orgânica $6 \mathrm{t} /$ ha $^{-1}$. Assim como na área foliar, observou-se também que a área foliar total obteve melhor desenvolvimento na presença de esterco caprino (F2) (figura 2B). 

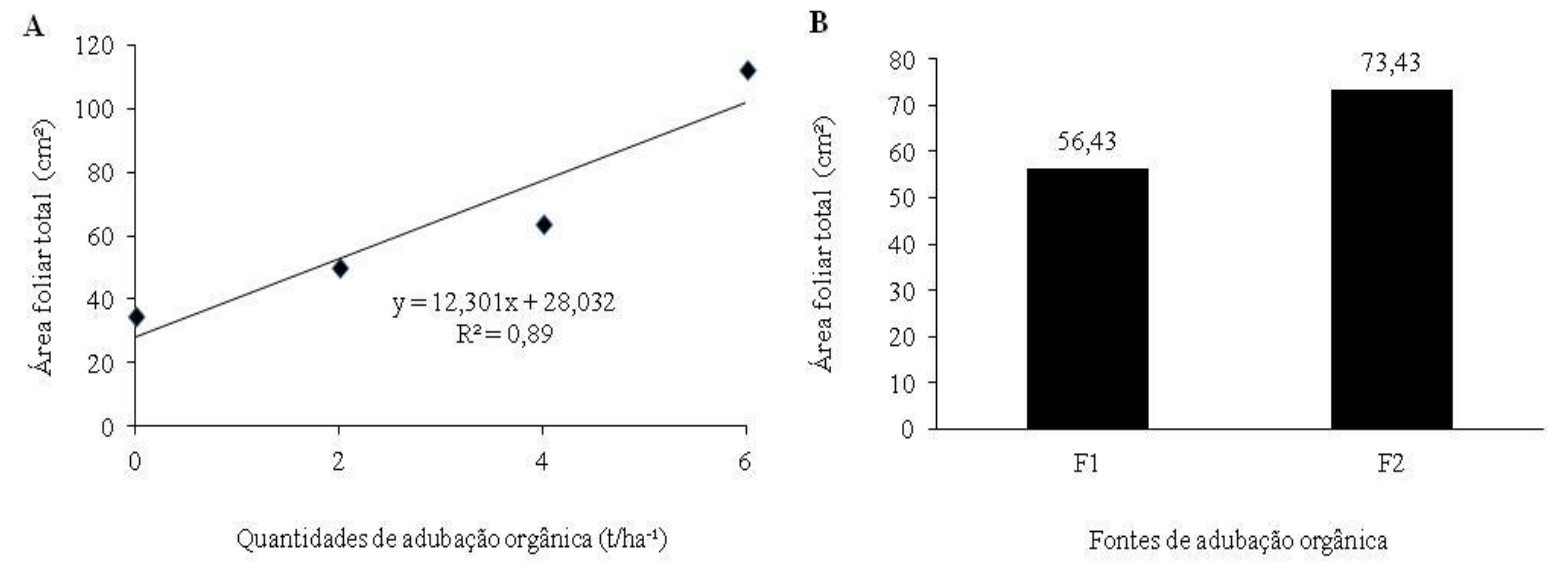

Figura 2: Efeito de quantidades de adubação orgânica (A) e fontes de adubação orgânica (B) na área foliar total de amendoim

Conforme a figura 3A, o aumento nas quantidades de adubação orgânica no amendoim proporcionaram um crescimento linear para o número de botões florais, obtendo na quantidade máxima de 6 t/ ha ${ }^{-1}$ uma média 47,62 número de botões florais se sobressaindo melhor em relação as demais quantidades (figura 3A). , ou seja, a dose máxima de urina de vaca $(120 \mathrm{~mL})$ se sobressaiu melhor em relação as demais doses.

Assim como nas demais variáveis observou-se que o esterco caprino (F2) proporcionou os melhores resultados no número de botões florais de amendoim (figura 3B).

Corroborando Andrade et al. (2014) estudando a qualidade de flores de girassol ornamental irrigada com água residuária e doses de esterco constataram que o número de botões florais obtiveram um número máximo de 13,46 botões florais na dose de $14 \%$ esterco.
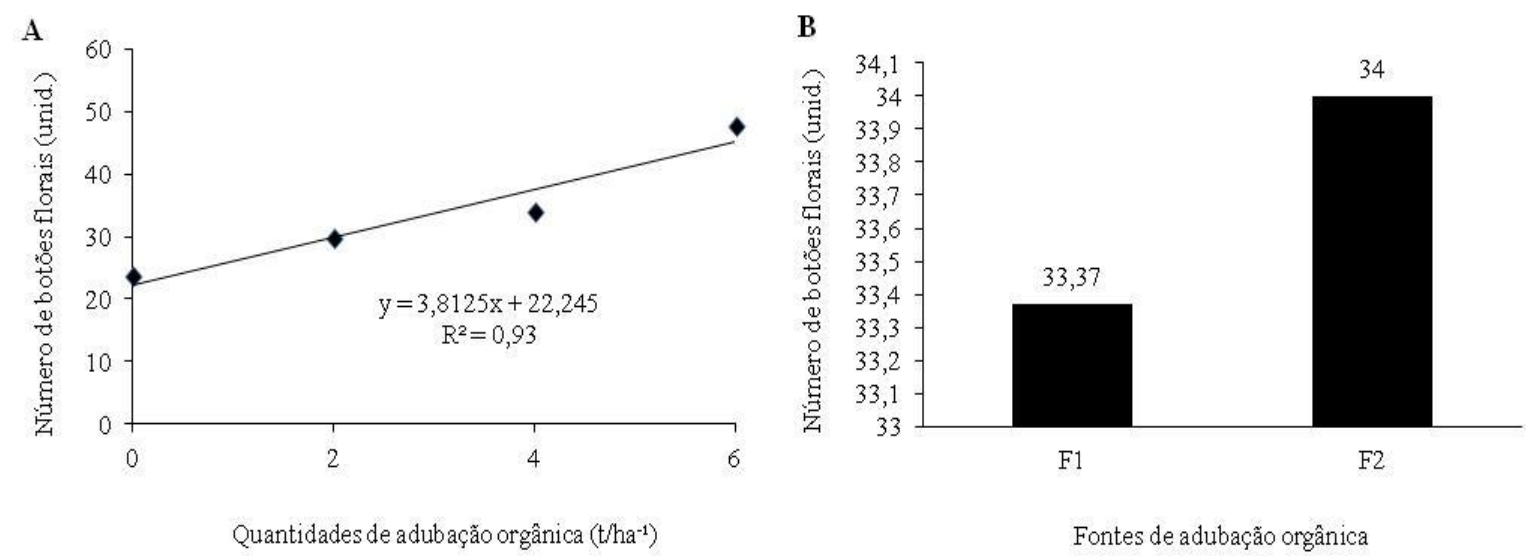

Figura 3: Efeito de quantidades de adubação orgânica (A) e fontes de adubação orgânica (B) no número de botões florais de amendoim 
As quantidades de adubação orgânica influenciaram estatisticamente o comprimento da raiz de amendoim, proporcionando um acréscimo conforme o seu aumento se enquadrando no tipo de regressão quadrática com comportamento convexo, onde os maiores valores foram encontrados na quantidade máxima 6 t/ ha ${ }^{-1}$ de adubação orgânica com o valor máximo de 22,25 cm (figura 4A). Em relação às fontes de adubação orgânica, foi observado para o comprimento da raiz que o esterco caprino resultou nos melhores resultados, influenciando estatisticamente a nível de ( $\mathrm{p}<0,05)$ (figura 4B).

Corroborando Sá et al. (2014) onde verificaram que o comprimento da raiz foi influenciado significativamente pelos níveis de esterco caprino na composição do substrato, havendo um aumento contínuo até a dose de $25 \%$ no comprimento da raiz principal com valores de 32,93 e 37,22 cm. Mendonça et al. (2007), em mudas de mamoeiro sob diferentes proporções de composto orgânico que continha esterco, observaram a maior dose testada, isto é, $40 \%$ obteve o melhor resultado para o comprimento da raiz.
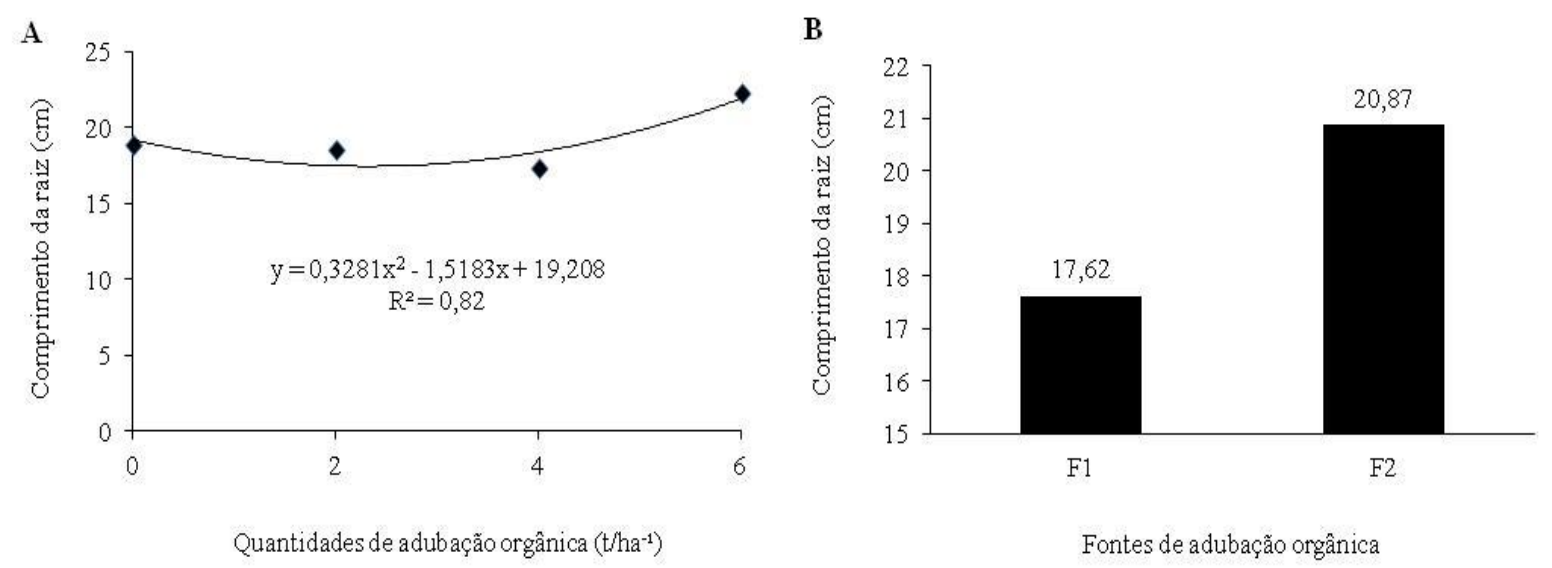

Figura 4: Efeito de quantidades de adubação orgânica (A) e fontes de adubação orgânica (B) no comprimento da raiz de amendoim

\section{CONSIDERAÇÕES FINAIS}

A quantidade máxima de 6 t/ ha-1 de adubação orgânica promoveu melhor o crescimento de amendoim.

Recomenda-se a utilização de esterco caprino no cultivo de amendoim. 


\section{REFERÊNCIAS BIBLIOGRÁFICAS}

ANDRADE, L. O. de.; GHEYI, H. R.; DIAS, N. da S.; NOBRE, R. G.; SOARES, F. A. L.; SATOS, N. Qualidade de flores de girassol ornamental irrigada com água residuária e doses de esterco. Revista Caatinga, Mossoró - Rn, v. 27, n. 3, p.142-149, jul. 2014.

BORGES, M.; BETTIOL, W. Agricultura Orgânica. EMBRAPA MEIO AMBIENTE. Ministério da Agricultura e Abastecimento. 2010, 2p. Disponível em www.cnpma.embrapa.br/informativo/mostra.informativo.php. Acesso em 15 de outubro de 2011.

CAMPOS, A. R. F.. Adubação orgânica e mineral sobre características produtivas do tomateiro cultivar Santa Cruz em ambiente protegido. 2013. 31 f. TCC (Graduação) Curso de Agronomia, Universidade Federal da Paraíba, Areia - Pb, 2013.

CONAB - Companhia Nacional de Abastecimento. Acompanhamento da safra brasileira: sexto levantamento da safra 2011/2012, março, 2012. Disponível em: <http://www.conab.gov.br/conteudosaliceweb2.mdic.gov.br>. Acesso em: 23 mar. 2015.

FERREIRA, D. F. Sisvar Versão 5.0. Lavras: UFLA, 2007.

FREITAS, G. A. de. 2011. Produção e área colhida de amendoim no nordeste. $3^{\mathrm{a}}$ ed. Banco do Nordeste, Fortaleza, 8 pp.

FREITAS, G. A. de; SOUSA, C. R. de; CAPONE, A.; AFFÉRRI, F. S.; MELO, A. V. de; SILVA, R. R. da. Adubação orgânica no sulco de plantio e sua influência no desenvolvimento do sorgo. J. Biotec. Biodivers., v. 3, N.1: pp. 61-67, Fev. 2012.

GRACIANO, E. S. A.; NOGUEIRA, R. J. M. C.; LIMA, D. R. M.; PACHECO, C. M.; SANTOS, R. C. Crescimento e capacidade fotossintética da cultivar de amendoim BR1 sob condições de salinidade. Revista Brasileira de Engenharia Agrícola Ambiental, Campina Grande-PB, v.15, n.8, p.794-800,2011.

PEREIRA, T. de A.; SOUTO, L. S.; SÁ, F. V. da S.; PAIVA, E. P de; SOUZA, D. L. de; SILVA, V. N. da; SOUZA, F. M. de. Esterco ovino como fonte orgânica alternativa para o cultivo do girassol no semiárido. ACSA - Agropecuária Científica no Semi-Árido, v. 10, n. 1, p. 59- 64, jan - mar, 2014.

PIMENTEL GOMES, F. Curso de estatística experimental. Piracicaba: FEALQ, p. 541, 2000.

SÁ, F. V. da S.; BERTINO, A. M. P.; FERREIRA, N. M.; BERTINO, A. M. P.; SOARES, L. da S.; MESQUITA, E. F. de. Formação de mudas de maracujazeiro amarelo com diferentes doses de esterco caprino e volumes do substrato. Magistra, Cruz das Almas - BA, V. 26, n. 4, p. 486 - 494, Out./Dez. 2014. 